\title{
Recomendaciones sobre la vacunación contra SARS-CoV-2/COVID-19 en pacientes con enfermedad renal crónica y trasplante renal
}

\author{
Ricardo Silvariño ${ }^{1,2,3,4}$, Alejandro Ferreiro ${ }^{1,2,4}$, Mariana Seija1 ${ }^{1}$, José Boggia1,3, Leonella Luzardo1, \\ Gabriela Otatti ${ }^{1}$, Marcelo Nin ${ }^{1}$, Liliana Gadola ${ }^{1,2}$, Victoria Frantchez ${ }^{5}$, Julio Medina ${ }^{5}$, Sofía San Román ${ }^{3}$, \\ Cecilia Baccino ${ }^{3}$, José Santiago ${ }^{1}$, Rossana Astesiano ${ }^{1}$, David Miller ${ }^{3}$, Pablo Ríos ${ }^{2}$, Laura Solá2, \\ Verónica Lamadrid², Óscar Noboa ${ }^{1,2}$, Renato de Ávila Kfourib y Eduardo Savio ${ }^{6}$ \\ ${ }^{1}$ Centro de Nefrología, Cátedra de Nefrología, Hospital de Clínicas, Facultad de Medicina, Universidad de la República, Montevideo, Uruguay; \\ ${ }^{2}$ Programa de Salud Renal, Sociedad Uruguaya de Nefrología, Facultad de Medicina-UdelaR, Fondo Nacional de Recursos, Ministerio de Salud \\ Pública, Montevideo, Uruguay; ${ }^{3}$ Comisión Directiva de la Sociedad Uruguaya de Nefrología, Montevideo, Uruguay; ${ }^{4}$ Sociedad Latinaomericana de \\ Nefrología e Hipertensión, Ciudad de Panamá, Panamá; ${ }^{5}$ Cátedra de Enfermedades Infecciosas, Hospital de Clínicas, Facultad de Medicina, \\ Universidad de la República, Montevideo, Uruguay; ${ }^{6}$ Comité de Inmunizaciones, Asociación Panamericana de Infectología, Montevideo, Uruguay
}

\section{Resumen}

- Los pacientes con enfermedad renal en todas sus etapas (ERC etapas 1-5, diálisis, trasplante renal) deben ser una población prioritaria en el plan de vacunación contra SARS-CoV-2.

- En todos los casos, la vacunación debe administrarse sin importar si los pacientes tuvieron antes COVID-19 o si tienen títulos de IgG positivos para SARS-CoV-2.

- Debe vacunarse a todos los pacientes con ERC avanzada, con o sin diálisis crónica, con los esquemas habituales propuestos para las diferentes vacunas disponibles en el medio.

- Debe vacunarse a todos los pacientes en lista de espera de trasplante renal. En quienes se encuentran programdos para trasplante inter vivos es deseable que completen la vacunación un mes antes del procedimiento.

- Hay que vacunar a todos los pacientes receptores de trasplante renal luego del primer mes del trasplante y aprovechar las situaciones clínicas de estabilidad y menor requerimiento de inmunosupresión. En las situaciones en que se administra timoglobulina o rituximab al trasplante se recomienda diferir la vacunación hasta el tercer mes. Cuando se indica tratamiento contra el rechazo (bolos de metilprednisolona, recambio plasmático terapéutico, gammaglobulina), se recomienda posponer la vacunación al menos dos semanas.

- Es preciso vacunar a los pacientes con enfermedades autoinmunitarias (enfermedades autoinmunitarias sistémicas, glomerulopatías), con o sin tratamiento inmunosupresor, de preferencia en el momento en que la enfermedad subyacente esté estable y en el mejor momento de la inmunosupresión.

Palabras clave: COVID-19. SARS-CoV-2. Enfermedad renal crónica. Vacunación.

\footnotetext{
Correspondencia:

*Ricardo Silvariño

E-mail: rsilvarino@gmail.com

Fecha de recepción: 07-03-2021

Fecha de aceptación: 08-03-2021

DOI: 10.24875/NEFRO.M21000011

Disponible en internet: 19-04-2021

Nefro Latinoam. 2021;18:71-79 www.nefrologialatinoamericana.com 2444-9032/@ 2021 Sociedad Latinoamericana de Nefrología e Hipertensión. Publicado por Permanyer. Este es un artículo open access bajo la licencia CC BY-NC-ND (http://creativecommons.org/licenses/by-nc-nd/4.0/).
} 


\section{SARS-CoV-2/COVID-19 vaccination in patients with chronic kidney disease and kidney transplantation: recommendations}

\section{Abstract}

- Patients with kidney disease (CKD stages 1-5, dialysis, kidney transplantation) should be a priority population in the vaccination plan against SARS-CoV-2.

- In all cases, vaccination should be administered regardless of whether patients previously had COVID-19 or have positive IgG titers for SARS-CoV-2.

- All patients with advanced CKD, with or without chronic dialysis, should be vaccinated with the usual schedules proposed for the different vaccines available.

- All patients on kidney transplant waiting list should be vaccinated. Those who are scheduled for intervivo transplantation, it is desirable to complete the vaccination proccess one month before the procedure.

- All kidney transplant recipients must be vaccinated after the first month after transplantation and take advantage of the clinical situation of stability and less immunosuppression. In situations in which thymoglobulin or rituximab is administered to the transplanted patient, it is recommended to defer vaccination until passes the third month. When anti-rejection treatment (methylprednisolone, therapeutic plasma exchange, i.v gamma globulin) is indicated, it is recommended to postpone vaccination for at least two weeks.

- It is mandatory to vaccinate patients with autoimmune diseases (systemic autoimmune diseases, glomerulopathies), with or without immunosuppressive treatment, preferably at the time when the underlying disease is in steady state and at the moment of lesser immunosuppression.preferably.

Key words: COVID-19. SARS-CoV-2. Chronic kidney disease. Vacccination.

Propósito de la recomendación. Este documento de recomendación elaborado por la Sociedad Latinoamericana de Nefrología e Hipertensión tiene como objetivo orientar a los médicos nefrólogos y de otras especialidades que asisten a pacientes con enfermedad renal crónica (ERC) en todas sus etapas (ERC de cualquier causa en seguimiento, diálisis o trasplante renal) en el proceso de vacunación contra el SARSCoV-2. Como consecuencia de la situación epidemiológica y los tiempos del proceso de elaboración de las vacunas disponibles, no se ha generado evidencia de potencia suficiente, por lo que las recomendaciones no se acompañan de su nivel de evidencia. Pese a ello, se partió de la premisa de que la priorización de la vacunación, dado el contexto epidemiológico local y mundial, es más beneficiosa que los efectos adversos potenciales. Estas recomendaciones se organizaron con base en grupos de asistencia y se consideraron situaciones especiales no excepcionales en la asistencia de pacientes con enfermedad renal.

Infección por SARS-CoV-2/COVID-19 y enfermedad renal. Los pacientes con ERC avanzada, en particular bajo diálisis crónica y trasplante renal, constituyen una población susceptible para la infección por SARSCoV-2, el desarrollo de la enfermedad (COVID-19) y una evolución más desfavorable cuando se los compara con la población general'1. La exposición y la infección por
SARS-CoV-2 en la población con ERC avanzada, y sobre todo en los pacientes en hemodiálisis crónica, son mucho más elevadas que en la población general. A la fragilidad impuesta por la ERC avanzada se suma la necesidad de mayor asistencia y permanencia de este grupo en centros de salud (consultas ambulatorias, centros de hemodiálisis, controles en diálisis peritoneal y policlínica de trasplante). Durante la "primer ola" de la infección se informó en centros europeos que 5\% a $20 \%$ de los pacientes que concurren a centros de hemodiálisis se infectarán con SARS-CoV- ${ }^{2}$. Esta prevalencia fue significativamente más baja en la población en diálisis peritoneal y trasplante renal, dado que son tratamientos instituidos de modo predominante en el domicilio ${ }^{3}$. Un grupo considerable de pacientes cursa la infección de forma asintomática. En estudios de seroprevalencia se ha registrado que $28 \%$ a $36 \%$ de los pacientes de centros de hemodiálisis (Londres, Nueva York) tienen anticuerpos contra SARS-CoV-2 y hasta $70 \%$ cuando se considera a los pacientes que además acuden a centros de rehabilitación física ${ }^{4}$. La elevada prevalencia de infección representa una altísima tasa de muerte. Cuando se compara la letalidad por COVID-19 de los pacientes con ERC con la de la población sin ERC que requiere hospitalización por COVID-19 se observa que éste es $30 \%$ y $130 \%$ más elevada ${ }^{5}$, con una tasa de letalidad informada de $16 \%$ a $32 \%^{5-7}$. El 
riesgo de muerte es excepcionalmente elevado en pacientes jóvenes bajo diálisis cuando se compara con la población sana de la misma edad ${ }^{8}$. La mortalidad comunicada es incluso más alta (1.28 veces mayor) en receptores de trasplante renal en comparación con pacientes sometidos a programa de diálisis crónica ${ }^{6}$. Este incremento de la mortalidad se explica, al menos en parte, por el compromiso inmunológico vinculado con la ERC y la inmunosupresión que reciben los trasplantados, además de que este grupo de pacientes tiene con frecuencia otras comorbilidades, como diabetes, obesidad, hipertensión arterial e insuficiencia cardiaca, que incrementan el riesgo de enfermarse y evolucionar de peor manera ${ }^{8,9}$.

La pandemia por SARS-CoV-2 ha generado también efectos indirectos poco reconocidos ${ }^{8}$, en especial en la población bajo diálisis crónica. El miedo frente a la amenaza de la infección ha producido en todo el mundo un mayor número de inasistencias a las sesiones de hemodiálisis, una disminución del número de consultas programadas de seguimiento en diálisis peritoneal y trasplante, y un menor número de consultas emergentes en esta población. Este cambio en las conductas de asistencia a diálisis y controles programados también se relaciona con incremento de la mortalidad ${ }^{8,10}$.

Vacunación contra SARS-CoV-2. Existe cierta "actitud pasiva" de la comunidad médica mundial respecto de la vacunación de algunos grupos de pacientes con ERC, sobre todo quienes reciben tratamiento de diálisis crónica, debido a la escasez de datos sobre seguridad y eficacia de las vacunas contra el SARS-CoV-2 en esta población. Esto se atribuye en parte a que no se ha incorporado ningún paciente en diálisis crónica a ninguno de los estudios mundiales de vacuna ${ }^{8}$. En una reciente revisión sistemática sobre la seguridad y eficacia de la vacunación contra COVID-19 en pacientes con enfermedad renal ${ }^{11}$ se identificó que $16 \%$ de los estudios excluyó explícitamente a pacientes con ERC (en cualquier estadio y circunstancia), $33 \%$ a pacientes con enfermedad renal grave y $44 \%$ dejó a "discreción del investigador" la incorporación de pacientes con enfermedad renal. Sólo $6 \%$ de los estudios usó un umbral de filtración glomerular específica $\left(\geq 60 \mathrm{ml} / \mathrm{min} / 1.73 \mathrm{~m}^{2}\right.$ ) para determinar la elegibilidad de los pacientes a incluir. De forma específica en estudios en fase 3 se incluyó a $39.4 \%$ de individuos con ERC leve a moderada y en el $60.6 \%$ restante se dejó abierta la posibilidad para su exclusión. El $78 \%$ de los estudios que incluían virus atenuados no vivos y atenuados vivos no incluyó a personas que recibían inmunosupresión para trasplante renal o glomerulopatías, sin ser explícita la exclusión en el resto de los estudios. En los estudios de fase 3 , el $93.5 \%$ excluyó a enfermos inmunodeprimidos, $64.5 \%$ a quienes recibían algún tipo de inmunosupresión y $32.3 \%$ a los que recibían inmunosupresión más allá de una dosis de prednisona de 10 a $20 \mathrm{mg} / \mathrm{dí}^{11}$.

Sin embargo, algunos datos indirectos señalan que la vacunación puede ser efectiva. Los pacientes en diálisis que han sobrevivido al COVID-19 tienen títulos de IgG contra el SARS-CoV-2 detectables hasta dos meses después de la infección ${ }^{12}$. Esto sugiere con solidez que una seroconversión vinculada con la vacunación es también esperable en este grupo de pacientes. De manera adicional, se dispone de amplia experiencia con la vacunación contra la influenza, hepatitis $B$ y neumococo en pacientes con ERC avanzada, en diálisis y trasplantados renales, en la que se han documentado por ejemplo tasas de seroconversión de 33\% a $80 \%$ para influenza ${ }^{13}$.

Vacunas disponibles contra el SARS-CoV-2. Hasta el momento, todas las vacunas con licencia en el mundo son inactivadas y por tanto sin riesgo teórico de uso en sujetos inmunocomprometidos, aunque en ellos la eficacia podría ser inferior.

Las vacunas disponibles pertenecen a cuatro grupos: basadas en ácidos nucleicos (RNA o DNA), basadas en vectores virales, basadas en subunidades proteicas y de virus inactivados ${ }^{14}$. Las vacunas basadas en ARN-m, una vez que entran en las células del hospedador, dan lugar a la producción de la proteína S del SARS-CoV-2 y estimulan al sistema inmunitario para producir anticuerpos contra ésta. Dentro de este grupo figuran las vacunas elaboradas por Pfizer (ARN Comirnaty@ [BNT162b2], Moderna y CureVac. Las vacunas basadas en ADN utilizan el mismo mecanismo descrito para las de RNA; la Inovio se halla en etapa más avanzada de evaluación. Las vacunas basadas en vectores virales combinan sectores del SARSCoV-2 y los incorporan a vectores virales (otros virus, por ejemplo adenovirus) que se inoculan en el hospedador. En este grupo se encuentran las vacunas de vector viral no replicador de AstraZeneca (AZD-1222/ ChAdOx1), Janssen, CanSino y Sputnik V. Las vacunas inactivadas emplean para producir inmunogenicidad virus inactivados y las vacunas de subunidades proteicas un conjunto de subunidades proteicas de éstos. Dentro de estos grupos se hallan la vacuna a virus inactivado CoronaVac (Sinovac), Sinopharm, Barath y la inactivada Novavax ${ }^{14}$. En la Tabla 1 se resumen las vacunas disponibles y sus principales características. 
Tabla 1. Vacunas disponibles y sus principales características

\begin{tabular}{|c|c|c|c|c|c|c|c|c|c|}
\hline Vacuna & Proveedor & $\begin{array}{l}\text { Tipo de } \\
\text { vacuna }\end{array}$ & Antígeno & Dosis & $\mathrm{N}^{0}$ de dosis & $\begin{array}{l}\text { Condiciones del } \\
\text { almacenamiento }\end{array}$ & $\begin{array}{l}\text { Eficacia contra } \\
\text { COVID-19 grave* }\end{array}$ & Eficacia global & $\begin{array}{l}\text { Aprobación } \\
\text { actual }\end{array}$ \\
\hline mRNA-1273 & Moderna (USA) & mRNA & $\begin{array}{l}\text { Proteína S de } \\
\text { longitud completa } \\
\text { con sustitución de } \\
\text { prolina }\end{array}$ & $100 \mu \mathrm{g}$ & $\begin{array}{l}2 \text { dosis } \\
\text { separadas por } \\
28 \text { días }\end{array}$ & $\begin{array}{l}-25^{\circ} \text { a }-15^{\circ} \mathrm{C} ; \\
2-8^{\circ} \mathrm{C} \text { por } 30 \text { días; } \\
\mathrm{T}^{\mathrm{o}} \\
\text { ambiente } \leq 12 \mathrm{~h}\end{array}$ & $\begin{array}{l}100 \% 14 \text { días } \\
\text { después de la } 2^{0} \\
\text { dosis (IC95\%) }\end{array}$ & $\begin{array}{l}92.1 \% 14 \text { días } \\
\text { después de } 1^{\circ} \\
\text { dosis (IC95\%, } \\
68.8 \%-99.1 \% \text { ); } 94.1 \% \\
14 \text { días después de } \\
2^{\circ} \text { dosis (IC95\%, } \\
89.3 \%-96.8 \% \text { ) }\end{array}$ & $\begin{array}{l}\text { AE: USA, } \\
\text { UE, RU }\end{array}$ \\
\hline BNT162b2 & $\begin{array}{l}\text { Pfizer-BioNTech } \\
\text { (USA) }\end{array}$ & mRNA & $\begin{array}{l}\text { Proteína S de } \\
\text { longitud completa } \\
\text { con sustitución de } \\
\text { prolina }\end{array}$ & $30 \mu \mathrm{g}$ & $\begin{array}{l}2 \text { dosis } \\
\text { separadas por } \\
21 \text { días }\end{array}$ & $\begin{array}{l}-80^{\circ} \text { a }-60^{\circ} \mathrm{C} ; \\
2-8^{\circ} \mathrm{C} \text { por } 5 \text { días; } \\
\mathrm{T}^{0} \text { ambiente } \leq 2 \mathrm{~h}\end{array}$ & $\begin{array}{l}88.9 \% \text { después de } \\
\text { la } 1^{\circ} \text { dosis (IC95\%, } \\
20.1 \%-99.7 \% \text { ) }\end{array}$ & $\begin{array}{l}52 \% \text { después de } 1^{\circ} \\
\text { dosis (IC95\%, } \\
29.5 \%-68.4 \%) ; 94.6 \% \\
7 \text { días después de } 2^{\circ} \\
\text { dosis (IC } 95 \% \text {, } \\
89.9 \%-97.3 \% \text { ) }\end{array}$ & $\begin{array}{l}\text { AE: USA, } \\
\text { UE, RU }\end{array}$ \\
\hline Ad26.CoV2.S & $\begin{array}{l}\text { Johnson \& } \\
\text { Johnson (USA) }\end{array}$ & $\begin{array}{l}\text { Vector } \\
\text { viral }\end{array}$ & $\begin{array}{l}\text { Vector de serotipo } \\
26 \text { de adenovirus } \\
\text { humano } \\
\text { recombinante, } \\
\text { incompetente para } \\
\text { la replicación, que } \\
\text { codifica a la } \\
\text { proténa S del } \\
\text { SARS-CoV-2 S } \\
\text { estabilizada de } \\
\text { longitud completa }\end{array}$ & $\begin{array}{l}5 \times 10^{3} \\
\text { partículas } \\
\text { virales }\end{array}$ & 1 dosis & $\begin{array}{l}-20^{\circ} \mathrm{C} ; 2-8^{\circ} \mathrm{C} \text { por } \\
3 \text { meses }\end{array}$ & $\begin{array}{l}85 \% \text { después de } 28 \\
\text { días; } 100 \% \text { después } \\
\text { de } 49 \text { días }\end{array}$ & $\begin{array}{l}72 \% \text { en USA; } 66 \% \text { en } \\
\text { LATAM; } 57 \% \text { en } \\
\text { SA (a los } 28 \text { días) }\end{array}$ & $\begin{array}{l}\text { AE iniciada } \\
\text { en USA }\end{array}$ \\
\hline $\begin{array}{l}\text { ChAd0 } \times 1 \\
(\text { AZS1222) }\end{array}$ & $\begin{array}{l}\text { AstraZeneca/ } \\
\text { Oxford (RU) }\end{array}$ & $\begin{array}{l}\text { Vector } \\
\text { viral }\end{array}$ & $\begin{array}{l}\text { Vector adenoviral } \\
\text { de chimpancé de } \\
\text { replicación } \\
\text { deficiente con la } \\
\text { proteína S del } \\
\text { SARS-CoV-2 }\end{array}$ & $\begin{array}{l}5 \times 10^{10} \\
\text { partículas } \\
\text { virales }\end{array}$ & $\begin{array}{l}2 \text { dosis } \\
\text { separadas por } \\
28 \text { días }\end{array}$ & $\begin{array}{l}2-8^{\circ} \mathrm{C} \text { por } \\
6 \text { meses }\end{array}$ & $\begin{array}{l}100 \% 21 \text { días } \\
\text { después de } 1^{\circ} \\
\text { dosis }\end{array}$ & $\begin{array}{l}64.1 \% \text { después de } 1^{\circ} \\
\text { dosis (IC95\%, } \\
50.5 \%-73.9 \%) ; 70.4 \% \\
14 \text { días después de } \\
2^{\circ} \text { dosis (IC } 95 \% \text {, } \\
54.8 \%-80.6 \%)\end{array}$ & $\begin{array}{l}\text { AE: OMS/ } \\
\text { Covax, RU, } \\
\text { India, } \\
\text { México }\end{array}$ \\
\hline NVX-CoV2373 & $\begin{array}{l}\text { Novavax, } \\
\text { Inc (USA) }\end{array}$ & $\begin{array}{l}\text { Subunidad } \\
\text { proteica }\end{array}$ & $\begin{array}{l}\text { Proteína S de } \\
\text { prefusión } \\
\text { recombinante de } \\
\text { longitud completa }\end{array}$ & $\begin{array}{l}5 \mu \mathrm{g} \text { de } \\
\text { proteína y } \\
50 \mu \mathrm{g} \text { de } \\
\text { adyuvante } \\
\text { matriz-M }\end{array}$ & 2 dosis & $\begin{array}{l}2-8^{\circ} \mathrm{C} \text { por } \\
6 \text { meses }\end{array}$ & Desconocida & $\begin{array}{l}89.3 \% \text { en } \mathrm{RU} \\
\text { después de } 2 \\
\text { dosis (IC95\%, } \\
75.2 \%-95.4 \%) ; 60 \% \\
\text { en SA (IC } 95 \% \text {, } \\
19.9 \%-80.1 \% \text { ) }\end{array}$ & $\begin{array}{l}\mathrm{AE} \\
\text { planificada }\end{array}$ \\
\hline
\end{tabular}


Tabla 1. Vacunas disponibles y sus principales características (Continuación)

\begin{tabular}{|c|c|c|c|c|c|c|c|c|c|}
\hline Vacuna & Proveedor & $\begin{array}{l}\text { Tipo de } \\
\text { vacuna }\end{array}$ & Antígeno & Dosis & $\mathrm{N}^{0}$ de dosis & $\begin{array}{l}\text { Condiciones del } \\
\text { almacenamiento }\end{array}$ & $\begin{array}{l}\text { Eficacia contra } \\
\text { COVID-19 grave* }\end{array}$ & Eficacia global & $\begin{array}{l}\text { Aprobación } \\
\text { actual }\end{array}$ \\
\hline CVnCoV & $\begin{array}{l}\text { CureVac/ } \\
\text { GlaxoSmithKline } \\
\text { (Alemania) }\end{array}$ & mRNA & $\begin{array}{l}\text { Proteína S de } \\
\text { longitud completa } \\
\text { estabilizada por } \\
\text { prefusión del virus } \\
\text { SARS-CoV-2 }\end{array}$ & $12 \mu \mathrm{g}$ & $\begin{array}{l}2 \text { dosis } \\
\text { separadas por } \\
28 \text { días }\end{array}$ & $\begin{array}{l}2-8^{\circ} \mathrm{C} \text { por } \\
3 \text { meses; } \\
\text { temperatura } \\
\text { ambiente por } \\
24 \mathrm{~h}\end{array}$ & Desconocida & Fase III en marcha & \\
\hline $\begin{array}{l}\text { Gam-COVID-Vac } \\
\text { (Sputnik V) }\end{array}$ & $\begin{array}{l}\text { Centro } \\
\text { Gamaleya } \\
\text { (Rusia) }\end{array}$ & $\begin{array}{l}\text { Vector } \\
\text { viral }\end{array}$ & $\begin{array}{l}\text { Glucoproteína S del } \\
\text { SARS-CoV-2 de } \\
\text { longitud completa } \\
\text { transportada por } \\
\text { vectores } \\
\text { adenovirales }\end{array}$ & $\begin{array}{l}10^{11} \text { partículas } \\
\text { virales por } \\
\text { dosis para } \\
\text { cada } \\
\text { adenovirus } \\
\text { recombinante }\end{array}$ & $\begin{array}{l}2 \text { dosis (primera } \\
\text { con rAd26 y } \\
\text { segunda con } \\
\text { rAd5) } \\
\text { separadas por } \\
21 \text { días }\end{array}$ & $\begin{array}{l}-18^{\circ} \mathrm{C} \text { (forma } \\
\text { líquida); } \\
2-8^{\circ} \mathrm{C} \text { (liofilizado) } \\
\text { por más de } \\
6 \text { meses }\end{array}$ & $\begin{array}{l}\text { 100\% } 21 \text { días } \\
\text { después de } 1^{0} \\
\text { dosis (IC95\%, } \\
94.4 \%-100 \%)\end{array}$ & $\begin{array}{l}87.6 \% 14 \text { días } \\
\text { después de } 1^{\circ} \\
\text { dosis (IC95\%, } \\
81.1 \%-91.8 \% \text { ); } 91.1 \% \\
7 \text { días después de } 2^{\circ} \\
\text { dosis (IC95\%, } \\
83.8 \%-95.1 \% \text { ) }\end{array}$ & $\begin{array}{l}\text { AE: Rusia, } \\
\text { Argentina, } \\
\text { Serbia, } \\
\text { EAU, } \\
\text { Argelia, } \\
\text { Palestina y } \\
\text { Egipto }\end{array}$ \\
\hline CoronaVac & $\begin{array}{l}\text { Sinovac Biotech } \\
\text { (China) }\end{array}$ & $\begin{array}{l}\text { Virus } \\
\text { inactivado }\end{array}$ & $\begin{array}{l}\text { Cepa CN02 } \\
\text { inactivada de } \\
\text { SARS-CoV-2 creada } \\
\text { a partir de células } \\
\text { Vero }\end{array}$ & $\begin{array}{l}3 \mu \mathrm{g} \text { con } \\
\text { adyuvante de } \\
\text { hidróxido de } \\
\text { aluminio }\end{array}$ & $\begin{array}{l}2 \text { dosis } \\
\text { separadas por } \\
14 \text { días }\end{array}$ & $\begin{array}{l}2-8^{\circ} \mathrm{C} \text {; vida útil } \\
\text { total } \\
\text { desconocida }\end{array}$ & Desconocida & $\begin{array}{l}\text { Datos de fase III no } \\
\text { publicados; eficacia } \\
\text { informada } 14 \text { días } \\
\text { después de } 2^{\circ} \text { dosis: } \\
50.38 \% \text { (formas } \\
\text { leves) y } 78 \% \text { (leves a } \\
\text { graves) en Brasil, } \\
65 \% \text { en Indonesia y } \\
91.25 \% \text { en Turquía }\end{array}$ & $\begin{array}{l}\text { AE: China, } \\
\text { Brasil, } \\
\text { Colombia, } \\
\text { Bolivia, } \\
\text { Chile, } \\
\text { Uruguay, } \\
\text { Turquía, } \\
\text { Indonesia y } \\
\text { Azerbaiyán }\end{array}$ \\
\hline BBIBP-CorV & $\begin{array}{l}\text { Sinopharm } \\
1 / 2 \text { (China) }\end{array}$ & $\begin{array}{l}\text { Virus } \\
\text { inactivado }\end{array}$ & $\begin{array}{l}\text { Cepa CN02 } \\
\text { inactivada de } \\
\text { SARS-CoV-2 creada } \\
\text { a partir de células } \\
\text { Vero }\end{array}$ & $\begin{array}{l}4 \mu \mathrm{g} \text { con } \\
\text { adyuvante de } \\
\text { hidróxido de } \\
\text { aluminio }\end{array}$ & $\begin{array}{l}2 \text { dosis } \\
\text { separadas por } \\
21 \text { días }\end{array}$ & $\begin{array}{l}2-8^{\circ} \mathrm{C} \text {; vida útil } \\
\text { total } \\
\text { desconocida }\end{array}$ & Desconocida & $\begin{array}{l}\text { Datos de fase III no } \\
\text { publicados; } \\
\text { informes (no } \\
\text { publicados) de } \\
\text { eficacia de } 79 \% \text { y } \\
86 \% \text {. }\end{array}$ & $\begin{array}{l}\text { AE: China, } \\
\text { EAU, } \\
\text { Baréin, } \\
\text { Serbia, } \\
\text { Perú y } \\
\text { Zimbabue }\end{array}$ \\
\hline
\end{tabular}

AE: autorización de emergencia; EAU: Emiratos Árabes Unidos; LATAM: Latinoamérica; mRNA: RNA mensajero; OMS: Organización Mundial de la Salud; RU: Reino Unido; SA: Sudáfrica; UE: unión Europea; USA: Estados Unidos. * La eficacia contra la enfermedad grave, que incluye la hospitalización relacionada con COVID-19, varía según sean la edad y el tiempo después de la vacunación. Adaptado de Creech CB, et al. ${ }^{27}$ 


\section{Recomendaciones de acuerdo con los grupos de pacientes}

Pacientes con ERC sin diálisis y pacientes bajo diálisis crónica (hemodiálisis y diálisis peritoneal). Al igual que otros grupos de pacientes con enfermedad renal, no se incluyeron en los estudios clínicos que evaluaron la efectividad de las vacunas. El hallazgo de títulos elevados de IgG dirigidos contra SARS-CoV-2 en pacientes bajo tratamiento con diálisis infectados previamente $^{12}$ podría sugerir que la vacuna tendría también un efecto protector en esta población.

- Se recomienda la vacunación de todos los pacientes con enfermedad renal crónica avanzada (con o sin plan de diálisis crónica) con los esquemas propuestos para las diferentes vacunas. No está definido aún si esta población requerirá un aumento de la dosis de inoculación tal y como ocurre con otras vacunas en este grupo, o si necesitarán revacunación temprana.

- El grupo de pacientes bajo hemodiálisis crónica puede vacunarse en el contexto del procedimiento en su centro (antes o después de la hemodiálisis), sin necesidad de cambiar el régimen de anticoagulación (véase la sección de situaciones especiales) ni suspender otros tratamientos que habitualmente recibe (p. ej., eritropoyetina).

- Se recomienda optimizar el acceso a la vacunación de los pacientes con ERC avanzada, diálisis y trasplante mediante el aprovechamiento de los medios logísticos existentes para el control de pacientes trasplantados, programas de ERC avanzada y unidades de hemodiálisis.

- En los casos que reciban inmunosupresión por alguna causa se actuará según sea la recomendación para este grupo particular.

- Es recomendable administrar la vacunación en todos los casos sin importar si los pacientes tuvieron previamente COVID-19 o si tienen títulos IgG positivos para SARS-CoV-2. La inmunidad adquirida por cursar la enfermedad se prolongará por algunos meses y por tanto quienes tuvieron COVID-19 deben recibir su primera dosis de inmunización cuando la autoridad sanitaria de cada país lo indique, luego de obtener la recuperación. Debe vigilarse el efecto de la emergencia de cepas mutantes sobre las vacunas disponibles.

Pacientes con trasplante renal funcional y en lista de espera. Los receptores de trasplante renal son pacientes con riesgo elevado de consecuencias graves por la infección por SARS-Cov-2, incluida la muerte en un alto porcentaje de los casos (20\%-30\% según las distintas series ${ }^{6,15,16}$. Estas consecuencias adquieren más relevancia en los primeros meses del trasplante ${ }^{6,15,16}$. Si bien los receptores de trasplantes no se incluyeron en los estudios clínicos, dada la experiencia con otras vacunas, no hay evidencia que sugiera que alguna de las vacunas disponibles contra COVID-19 no sea segura y protectora en este grupo de enfermos. El antecedente de seroconversión confirmada en más del $70 \%$ de los pacientes con trasplante renal infectados por SARS-CoV-2 apoya la hipótesis de que la vacunación puede ser efectiva en este grupo ${ }^{17}$. Sin embrago, se ha observado que hasta en $20 \%$ hay un descenso de los títulos de anticuerpos en el tiempo. Los factores relacionados con este descenso fueron el consumo de inhibidores de la calcineurina y los esteroides ${ }^{18}$. Por lo tanto, al igual que otros grupos de pacientes bajo tratamiento inmunosupresor, es posible que la respuesta esperada frente a la vacunación se atenúe en su magnitud y duración en comparación con la población general ${ }^{19,20}$. Al margen de las consideraciones realizadas, esta población debe vacunarse contra SARS-CoV-217,21.

- Se recomienda la vacunación en todos los pacientes en lista de espera de trasplante. En quienes se encuentran programados para trasplante inter vivos es deseable que completen la vacunación un mes antes del procedimiento y al menos dos semanas antes del trasplante renal como plazo mínimo.

- No se recomienda excluir al paciente en lista de trasplante durante ningún período tras la primera 0 segunda dosis de la vacuna. Lo riesgos y beneficios deben individualizarse en cada caso.

- Se recomienda la vacunación de todos los receptores de trasplante renal luego de transcurrido el primer mes del trasplante.

- En las situaciones en que se administra timoglobulina o rituximab al trasplante, se recomienda diferir la vacunación hasta el tercer mes luego del trasplante.

- Si el paciente ha recibido tratamiento contra el rechazo (bolos de metilprednisolona, recambio plasmático terapéutico, gammaglobulina) es recomendable diferir la vacunación al menos dos semanas después del procedimiento.

- Se recomienda aprovechar las situaciones clínicas de estabilidad y menor requerimiento de inmunosupresión para indicar la vacunación. No es recomendable retrasar excesivamente la vacunación.

- Las consideraciones sobre la oportunidad y eventuales modificaciones del tratamiento inmunosupresor se muestran en la Tabla 2. 
Tabla 2. Consideraciones sobre la oportunidad de la vacunación y posibles modificaciones al tratamiento inmunosupresor

\begin{tabular}{|c|c|}
\hline Medicación & $\begin{array}{l}\text { Oportunidad de vacunación/modificación del tratamiento } \\
\text { inmunosupresor }\end{array}$ \\
\hline $\begin{array}{l}\text { Hidroxicloroquina; inmunoglobulinas intravenosas; } \\
\text { glucocorticoides (dosis equivalente a }<20 \text { mg/día de prednisona) }\end{array}$ & $\begin{array}{l}\text { No requiere modificación del tratamiento inmunosupresor ni } \\
\text { de la oportunidad de la vacunación }\end{array}$ \\
\hline $\begin{array}{l}\text { Micofenolato; azatioprina; inhibidores de la calcineurina; } \\
\text { ciclofosfamida oral; sulfasalazina; leflunomida; anti-TNF; belimumab. } \\
\text { Glucocorticoides (dosis equivalente a prednisona } \geq 20 \text { mg/día) }\end{array}$ & $\begin{array}{l}\text { No requiere modificación del tratamiento inmunosupresor ni } \\
\text { de la oportunidad de la vacunación }\end{array}$ \\
\hline Metotrexato & $\begin{array}{l}\text { Para cualquier esquema de administración, programar la } \\
\text { siguiente dosis de metotrexato una semana después de la } \\
\text { vacunación }\end{array}$ \\
\hline Ciclofosfamida intravenosa & $\begin{array}{l}\text { Para aquellos pacientes que ya recibieron ciclofosfamida } \\
\text { diferir la vacunación dos semanas luego de la última dosis }\end{array}$ \\
\hline Rituximab & $\begin{array}{l}\text { Programar la vacunación de modo que la serie de vacunas se } \\
\text { inicie aproximadamente } 4 \text { semanas antes del próximo ciclo } \\
\text { programado de rituximab. Después de la vacunación retrasar } \\
\text { la administración de rituximab 2-4 semanas luego de la última } \\
\text { dosis, si la actividad de la enfermedad lo permite }\end{array}$ \\
\hline
\end{tabular}

TNF: factor de necrosis tumoral. Adaptado a partir de American College of Rheumatology. ${ }^{19}$

- Se recomienda administrar la vacunación en todos los casos al margen de que los pacientes tuvieran con anterioridad COVID-19 o tengan títulos IgG positivos para SARS-CoV-2.

Pacientes con enfermedades autoinmunitarias/ inflamatorias o bajo tratamiento inmunosupresor (enfermedades autoinmunitarias sistémicas, glomerulopatías, no incluido el trasplante renal). Los pacientes bajo tratamiento inmunosupresor han mostrado en todo el mundo una mayor prevalencia de hospitalización por COVID-19 y una tasa de mortalidad más elevada en comparación con la población general ${ }^{19,22}$. Los pacientes inmunodeprimidos no se han incluido en la mayor parte de los estudios clínicos de las vacunas para COVID-1922. Es posible que la respuesta esperada frente a la vacunación para muchos pacientes bajo tratamiento inmunosupresor/ inmunomodulador se atenúe en su magnitud y duración en comparación con la población general19,20,22; sin embargo, ello no constituye un argumento de peso para no indicar la vacunación ${ }^{19,20,22}$. Existe un riesgo teórico de "brote" o agravamiento de la enfermedad autoinmunitaria después de la vacunación, aunque el beneficio de la vacuna para los pacientes con enfermedades autoinmunitarias supera el riesgo potencial de cualquier posible manifestación de autoinmunidad ${ }^{19,20,22}$. En función de lo analizado y con base en las recomendaciones del American College of Rheumatology y la European Alliance of Associations for Rheumatology ${ }^{19,20}$ se recomienda lo siguiente:

- Los pacientes con enfermedades autoinmunitarias deben recibir vacunación contra SARS-CoV-2, de acuerdo con lo planificado y según su grupo de edad y comorbilidades.

- Vacunar, de preferencia, en un momento en que la enfermedad de base se halle estable o sin actividad reciente. En la Tabla 2 se muestran las consideraciones pertinentes acerca del mejor momento de indicar la vacunación en función del tratamiento inmunosupresor, así como eventuales modificaciones a éste en caso de requerirse.

- Los pacientes (con o sin enfermedades autoinmunitarias/inflamatorias) que reciben tratamiento inmunosupresor deben recibir vacunación contra SARSCoV-2, de acuerdo con lo planificado y según su grupo de edad y comorbilidades.

- Con excepción de las vacunas con virus vivos o vectores replicantes (que no se recomiendan en este grupo de pacientes), no existe preferencia de una vacuna sobre otra para administrarse.

- No se recomiendan cambios en el esquema de administración (dosis, separación entre dosis) en este grupo de pacientes. 
- No realizar pruebas serológicos en busca de anticuerpos contra SARS-CoV-2 previo ni posterior a la vacunación. Tampoco se recomienda determinar sistemáticamente con estudios de laboratorio la presencia de "brote" de su enfermedad autoinmunitaria si no hay otras manifestaciones que así lo indiquen.

- No interrumpir el tratamiento inmunosupresor para la administración de la vacuna. Esto implicaría riesgo de brote o empeoramiento de su enfermedad. Tampoco modificar el esquema de administración del tratamiento inmunosupresor.

- Administrar la inmunización en todos los casos sin importar si los pacientes tuvieron previamente COVID-19 o si tienen títulos IgG positivos para SARS-CoV-2.

\section{Casos particulares}

\section{Pacientes anticoagulados, con trombocitopenia} u otras situaciones que los predispongan al sangrado. Existe amplia experiencia en la vacunación intramuscular en este grupo de pacientes. Regularmente reciben vacunación antigripal (anual), así como otras vacunas por esa vía sin que ello ocasione complicaciones mayores ${ }^{23}$. Ninguno de estos escenarios supone una contraindicación para la vacunación.

\section{Antagonistas de la vitamina K (warfarina)}

- En los pacientes anticoagulados con antagonistas de la vitamina $\mathrm{K}$ (warfarina) no debe suspenderse la anticoagulación para administrar la vacuna ${ }^{24,25}$.

- En los pacientes que reciben fármacos antivitamina $\mathrm{K}$ (warfarina) es conveniente confirmar que se encuentran dentro de su intervalo de INR objetivo al administrarse la vacuna ${ }^{24,25}$.

\section{Anticoagulantes orales de acción directa (dabigatrán, rivaroxabán, apixabán)}

- En los pacientes anticoagulados con anticoagulantes directos (dabigatrán, rivaroxabán, apixabán) no debe suspenderse la anticoagulación para administrar la vacuna $^{24,25}$.

- En los pacientes en tratamiento con anticoagulantes orales de acción directa (dabigatrán, rivaroxabán, apixabán) se debe evitar el efecto máximo del fármaco al programar la vacunación ${ }^{24,25}$. Para ello se puede retrasar la dosis del anticoagulante el día de la vacunación hasta después de administrada la vacuna ${ }^{26}$.

\section{Heparinas de bajo peso molecular}

- En los pacientes bajo tratamiento con heparinas de bajo peso molecular se debe evitar el momento de máximo efecto del fármaco al programar la vacunación ${ }^{24,25}$. Para ello se puede retrasar la dosis correspondiente al día de la vacunación hasta después de administrar la vacuna ${ }^{26}$.

\section{Antiagregantes plaquetarios (AAS, clopidogrel, ticagrelor, plasugrel)}

- Se puede mantener el tratamiento habitual sin necesidad de ningún ajuste el día de la vacunación ${ }^{26}$.

\section{Trombocitopenia}

- En pacientes con trombocitopenia persistente se recomienda ${ }^{25}$ :

- Si el recuento plaquetario es $>50,000 / \mathrm{mm}^{3}$ no se requieren medidas especiales

- Si el recuento plaquetario es de 30,000 a $50,000 / \mathrm{mm}^{3}$ se recomienda comprimir la zona de punción (sin frotar) durante al menos tres minutos.

- Si el recuento es $<30,000 / \mathrm{mm}^{3}$ se recomienda consultar al hematólogo para que establezca las indicaciones específicas apropiadas a la situación.

- En todos los casos se recomienda la administración con aguja fina (no mayor de $23 \mathrm{G}$ ) y presionar la zona de punción (sin frotar) al menos durante tres minutos ${ }^{24,25}$.

- En pacientes con otras anomalías hematológicas ( $p$. ej., hemofilia) se recomienda consultar al hematólogo para que señale las indicaciones específicas apropiadas a la situación ${ }^{24,25}$.

Pacientes con mieloma múltiple (MM). Los pacientes deben vacunarse dado el riesgo de mortalidad aumentada. Por razones de seguridad en este grupo, están aprobadas las vacunas de plataformas RNA-m. En caso de MM activo, no debe suspenderse el tratamiento específico. En caso de enfermedad estable y posible suspensión temporal del tratamiento, se recomienda suspenderlo siete días antes de la primera dosis hasta siete días después de recibir la segunda.

Otras vacunas. Es importante destacar que los pacientes con ERC deben tener además su calendario de vacunaciones actualizado contra otras enfermedades transmisibles y que los profesionales de la salud deben estar adecuadamente vacunados contra ellas. 


\section{Bibliografías}

1. Williamson EJ, Walker AJ, Bhaskaran K, Bacon S, Bates C, Morton CE, et al. Factors associated with COVID-19-related death using OpenSAFELY. Nature. 2020;584:430-436.

2. de Meester J, de Bacquer D, Naesens M, Meijers B, Couttenye MM, de Vriese AS. Incidence, characteristics, and outcome of COVID-19 in adults on kidney replacement therapy: a regionwide registry study. J Am Soc Nephrol. 2021;32:385-396.

3. Jiang HJ, Tang H, Xiong F, Chen WL, Tian JB, Sun J, et al. COVID-19 in peritoneal dialysis patients. Clin J Am Soc Nephrol. 2021;16:121-123.

4. Clarke C, Prendecki M, Dhutia A, Ali MA, Sajjad H, Shivakumar O, et al. High prevalence of asymptomatic COVID-19 infection in hemodialysis patients detected using serologic screening. J Am Soc Nephrol. 2020;31:1969-1975.

5. Ng JH, Hirsch JS, Wanchoo R, Sachdeva M, Sakhiya V, Hong S, et al. Outcomes of patients with end-stage kidney disease hospitalized with COVID-19. Kidney Int. 2020;98:1530-1539.

6. Jager KJ, Kramer A, Chesnaye NC, Couchoud C, Sánchez-Álvarez JE, Garneata L, et al. Results from the ERA-EDTA Registry indicate a high mortality due to COVID-19 in dialysis patients and kidney transplant recipients across Europe. Kidney Int. 2020;98:1540-1548.

7. Turgutalp K, Ozturk S, Arici M, Eren N, Gorgulu N, Islam M, et al. Determinants of mortality in a large group of hemodialysis patients hospitalized for COVID-19. BMC Nephrol. 2021;22:1-10.

8. Francis A, Baigent C, Ikizler TA, Cockwell P, Jha V. The urgent need to vaccinate dialysis patients against severe acute respiratory syndrome coronavirus 2: a call to action. Kidney Int. 2021;5-7.

9. Gagliardi I, Patella G, Michael A, Serra R, Provenzano M, Andreucci M. COVID-19 and the kidney: from epidemiology to clinical practice. J Clin Med. 2020;9:2506.

10. Lee J, Steel J, Roumelioti ME, Erickson S, Myaskovsky L, Yabes JG, et al. Psychosocial impact of COVID-19 pandemic on patients with end-stage kidney disease on hemodialysis. Kidney. 360 2020;1:1390-1397.

11. Glenn DA, Hegde A, Kotzen E, Walter EB, Kshirsagar AV, Falk R, et al. Systematic review of safety and efficacy of COVID-19 vaccines in patients with kidney disease. Kidney Int Reports. 2021. doi:10.1016/j. ekir.2021.02.011.

12. Shaikh A, Zeldis E, Campbell KN, Chan L. Prolonged SARS-CoV-2 viral RNA shedding and IgG antibody response to SARS-CoV-2 in patients on hemodialysis. Clin J Am Soc Nephrol. 2021;16:290-292.

13. Krueger KM, Ison MG, Ghossein C. Practical guide to vaccination in all stages of CKD, including patients treated by dialysis or kidney transplantation. Am J Kidney Dis. 2020;75:417-425.

14. Comisión Nacional Asesora de Vacunaciones. Vacunas contra SARSCoV-2 COVID 19. Aportes para la consideración de su uso en Uruguay, Montevideo, Uruguay, 2021.
15. Yi SG, Rogers AW, Saharia A, Aoun M, Faour R, Abdelrahim M, et al. Early experience with COVID-19 and solid organ transplantation at a US high-volume transplant center. Transplantation. 2020;104:2208-2214.

16. Craig-Schapiro R, Salinas T, Lubetzky M, Abel BT, Sultan S, Lee JR, et al. COVID-19 outcomes in patients waitlisted for kidney transplantation and kidney transplant recipients. Am J Transplant. 2020;1-10.

17. Federación de Asociaciones Científico Médicas Españolas. Recomendaciones FACME para la vacunación frente a COVID-19 en grupos de potencial riesgo. Administración de la vacuna frente a COVID-19 en pacientes candidatos y receptores de trasplantes de órganos sólidos. España, 2021.

18. Chavarot N, Leruez-Ville M, Scemla A, Burger C, Amrouche L, Rouzaud C, et al. Decline and loss of anti-SARS-CoV-2 antibodies in kidney transplant recipients in the 6 months following SARS-CoV-2 infection. Kidney Int. 2021;99:486-488.

19. American College of Rheumatology. COVID-19 vaccine clinical guidance summary for patients with rheumatic and musculoskeletal diseases. Developed by the ACR COVID-19 Vaccine Clinical Guidance Task Force. Atlanta, USA, 2021.

20. European Alliance of Associations for Rheumatology. EULAR View-points on SARS-CoV-2 vaccination in patients with RMDs, 2021.

21. British Transplantation Society. British Transplantation Society Position Statement on Vaccination against COVID-19 in Solid Organ and Islet Transplant Recipients (adults, children and young people), 2021.

22. Federación de Asociaciones Científico Médicas Españolas. Recomendaciones FACME para la vacunación frente a COVID-19 en grupos de potencial riesgo. Administración de la vacuna frente a COVID-19 en pacientes con inmunodeficiencias o en tratamiento inmunosupresor o inmunomodulador. España, 2021.

23. Casajuana J, Iglesias B, Fàbregas M, Fina F, Vallès JA, Aragonès R, et al. Safety of intramuscular influenza vaccine in patients receiving oral anticoagulation therapy: a single blinded multi-centre randomized controlled clinical trial. BMC Blood Disord. 2008;8:1-7.

24. Sociedad Española de Trombosis y Hemostasia. Vacunas frente a COVID-19 en pacientes con tratamiento anticoagulante o trastornos hemorrágicos. España, 2021.

25. Federación de Asociaciones Científico Médicas Españolas. Recomendaciones FACME para la vacunación frente a COVID-19 en grupos de potencial riesgo. ¿Se debe administrar la vacuna frente a COVID-19 a pacientes anticoagulados o con trastornos de la coagulación? España, 2021.

26. Sociedad Uruguaya de Cardiología. Recomendaciones de la Sociedad Uruguaya de Cardiología para la administración de vacunas contra la COVID-19 en pacientes bajo tratamiento anticoagulante y antiagregante. Montevideo, Uruguay, 2021.

27. Creech CB, Walker SC, Samuels RJ. SARS-CoV-2 Vaccines. JAMA. 2021;26-28. 